\title{
Photoelectrocatalytic oxidation of metal-EDTA and recovery of metals by electrodeposition with a rotating cathode
}

\author{
Yutong Chen ${ }^{\mathrm{a}, \mathrm{c}}$, Xu Zhao ${ }^{\mathrm{a}, \mathrm{b}, *}$, Wei Guan ${ }^{\mathrm{a}, \mathrm{d}}$, Di Cao ${ }^{\mathrm{a}, \mathrm{b}}$, Tao Guo ${ }^{\mathrm{a}}$, Xiufang Zhang ${ }^{\mathrm{c}, *}$, Yan Wang ${ }^{\mathrm{a}, *}$ \\ ${ }^{a}$ Key Laboratory of Drinking Water Science and Technology, Research Center for Eco-Environmental Sciences, Chinese Academy of Sciences, Beijing 100085, China \\ ${ }^{\mathrm{b}}$ University of Chinese Academy of Sciences, Beijing 100049, China \\ ' School of Light Industry and Chemical Engineering, Dalian Polytechnic University, Dalian 116034, China \\ ${ }^{\mathrm{d}}$ Chongqing Key Laboratory of Environmental Materials \& Remediation Technologies, Chongqing University of Arts and Sciences, Chongqing 402160, China
}

\section{H I G H L I G H T S}

- A photoelectro-reactor with a rotating cathode was designed for metal recovery.

- The cathodic rotation was beneficial for recovery of various metal-EDTA complexes.

- Recovery ratio of Cu was increased by $36.56 \%$ at the rotation speed of $100 \mathrm{rpm}$.

\section{A R T I C L E I N F O}

\section{Article history:}

Received 31 December 2016

Received in revised form 3 May 2017

Accepted 5 May 2017

Available online 6 May 2017

\section{Keywords:}

Photoelectrocatalysis

Rotating cathode

Metal-EDTA

Metal recovery

\section{G R A P H I C A L A B S T R A C T}
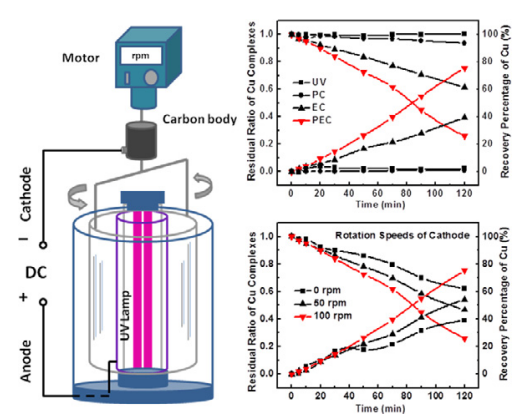

\begin{abstract}
A B S T R A C T
In this work, a photoelectrocatalytic reactor with a rotating cathode was designed for the destruction of metal complexes and recovery of liberated metal ions. The effects of rotating speed, current density, initial $\mathrm{pH}$ and initial $\mathrm{Cu}-\mathrm{EDTA}$ concentration on the recovery of $\mathrm{Cu}$ and destruction of $\mathrm{Cu}$ complexes were investigated. At cathode rotation speed of $100 \mathrm{rpm}$, initial pH of 3.18 and current density of $0.5 \mathrm{~mA} /$ $\mathrm{cm}^{2}$, the recovery percentage of $\mathrm{Cu}$ and destruction of the $\mathrm{Cu}$ complexes were increased to be $75.54 \%$ and $74.18 \%$ from $38.98 \%$ and $37.92 \%$ at $0 \mathrm{rpm}$ rotation speed within $120 \mathrm{~min}$, respectively. Furthermore, the destruction of Co-EDTA, Ni-EDTA and Zn-EDTA complexes using the rotating cathode were investigated. The $\mathrm{Co}^{2+}, \mathrm{Ni}^{2+}$ and $\mathrm{Zn}^{2+}$ recovery percentage was increased by $29 \%, 19 \%$ and $18 \%$ with the optimal speed of cathode, respectively. The recovered product from the cathodic electroreduction was all crystallized. The treatment performance of the reactor for the first 5 cycles had a slight downward trend, and then the capability of the reactor tended to be stable. The photoelectroctalytic reactor with the rotating cathode exhibited the high efficiency for the recovery of liberated metal ions and destruction of metal-EDTA complexes.
\end{abstract}

(c) 2017 Elsevier B.V. All rights reserved.

\footnotetext{
* Corresponding authors at: Key Laboratory of Drinking Water Science and Technology, Research Center for Eco-Environmental Sciences, Chinese Academy of Sciences, Beijing 100085, China (X. Zhao).
E-mail addresses: zhaoxu@rcees.ac.cn

(X. Zhang), yanwang@rcees.ac.cn (Y. Wang).
}

\section{Introduction}

Heavy metal wastewater has been a major concern in the field of water pollution. The conventional precipitation processes are limited for the removal of metal ions in the presence of chelating agents such as tartrate, citrate and ethylenediaminetetracetic acid (EDTA) [1]. In recent years, advanced oxidation processes (AOPs) 
including photocatalysis [2,3], electrochemical membrane [4] and $\mathrm{UV} / \mathrm{H}_{2} \mathrm{O}_{2}$ [5] have been reported for the treatment of the organic metal complexes. Not only destruction of metal complexes, efficient metal recovery was desired.

Photoelectrocatalytic (PEC) oxidation process in which a diminutive positive potential is applied on the semiconductor photoanode has proven to be more efficient than single photocatalytic (PC) process [6]. In PEC systems, the application of a small external bias decreases the recombination rate of photogenerated electronhole pairs and thus increasing the photocatalytic activity of the semiconductor photocatalyst [7]. In our previous works, the destruction of $\mathrm{Cu}-\mathrm{EDTA}, \mathrm{Cu}(\mathrm{CN})_{3}^{2-}$ and Ni-EDTA has been achieved at the semiconductor photoanode in PEC process, and the simultaneous recovery of the liberated metal ions at the cathode was reported $[8,9]$. Through the experiments, it was exhibited that the mass transfer rate near the cathode was low and the recovery efficiencies of metals were desired to be increased.

The design of efficient electrolytic cell has been guided toward the optimization of the excellent dynamic structure, the large mass transport coefficient and the space time yield [10-13]. For wastewater treatment, there was an electro-Fenton process reactor with a rotating disk electrode as cathode in which hydrogen peroxide was in situ generated [14]. In order to relieve the adverse effect of the low utilization rate arised from the high recombination of the photon-electron and photo-induced pairs, Buttetfield et al. recommended a large-scale vortex reactor [15]. The results represented a proof-of-concept of the electric field enhancement approach in large scale PEC reactors. The photocatalytic reactor with the rotating disk has been detailedly explained in mixing studies, where the mass transfer efficiency of the rotating disk, light intensity of the rotating and degradation mechanism of organic contaminants were studied $[16,17]$. A systematic electrochemical research was carried out to permit the selective silver electroseparation with minimum interference from the actual leaching solution by a rotating cylinder electrode reactor [18]. The mass transport of the rotating cylinder electrode reactor for the metal ions recovery from simulated wastewater was investigated [19]. Meanwhile, it was analyzed that the electrochemical recovery of nickel from synthetic solutions simulating plating rinsing discharges [20]. However, there is no mention on the removal of pollutants at photoanode with simultaneous recovery of metal ions at the rotating electrode yet.

Herein, a PEC reactor with a rotating tubular cathode was designed in order to improve the mass transfer and the cathodic metal recovery efficiency. The PEC reactor was comprised of a UV lamp which was in the center of the tubular $\mathrm{TiO}_{2} / \mathrm{Ti}$ mesh anode, and a concentrically rotating cylinder cathode driven by a motor in order to promote turbulence to enhance mass transfer. The effects of the rotating speed of the cathode, current density, pH values and aeration were investigated. The capacity of this PEC system was also checked based on the recovery of different heavy metals from their EDTA complexes. In the meantime, the recovery products of metal ions were investigated.

\section{Experimental section}

\subsection{Chemicals}

Ethylenediaminetetraacetic acid disodium salt dehydrate $\left(\mathrm{Na}_{2}-\right.$ EDTA), nickel (II) chloride hexahydrate $\left(\mathrm{NiCl}_{2} \cdot 6 \mathrm{H}_{2} \mathrm{O}\right)$, cobalt (II) sulfate heptahydrate $\left(\mathrm{CoSO}_{4} \cdot 7 \mathrm{H}_{2} \mathrm{O}\right)$, zinc sulfate heptahydrate $\left(\mathrm{ZnSO}_{4} \cdot 7 \mathrm{H}_{2} \mathrm{O}\right)$, sodium sulfate anhydrous $\left(\mathrm{Na}_{2} \mathrm{SO}_{4}\right)$, Copper sulfate $\left(\mathrm{CuSO}_{4}\right)$, and 5, 5-dimethyl-pyrroline-N-oxide (DMPO) were all purchased commercially and without any purification. Simulated wastewater was prepared by mixing the divalent metal salts and
$\mathrm{Na}_{2}$ EDTA with a mixed molar ratio of $1: 1.1 \mathrm{mM} \mathrm{NaOH}$ or $\mathrm{H}_{2} \mathrm{SO}_{4}$ was used to adjust the $\mathrm{pH}$ value of solutions. $\mathrm{H}_{2} \mathrm{SO}_{4}$ and $\mathrm{NaOH}$ were often used to control the $\mathrm{pH}$ as a common acid-base regulator [21]. Other reagents of analytical grade were obtained from Beijing Chemical Company (PR China) and used as received. Deionized water was used to prepare and dilute solutions.

\subsection{Experimental apparatus}

The diagrammatic sketch of the reactor that used in this research was shown in Fig. 1. The PEC experiments with the rotating cathode were performed in the tailor-made cell of $600 \mathrm{~mL}$ capacity, $94 \mathrm{~mm}$ internal diameter and $145 \mathrm{~mm}$ high. The tubular mesh $\mathrm{TiO}_{2} / \mathrm{Ti}$ (50 mm diameter, $100 \mathrm{~mm}$ high) was used as anode. A tubular reticulated titanium (100 $\mathrm{mm}$ diameter, $65 \mathrm{~mm}$ high) was used as cathode. The actual area of the cathode was determined to be $136.1 \mathrm{~cm}^{2}$ by the calculation area of cathode minus the value of the mesh total area. The actual current in the experiment was obtained by multiplying the current density by the actual working area of the electrode. Before being used, the titanium mesh was rinsed using $0.1 \mathrm{M} \mathrm{HCl}$ solution. The distance between the titanium cathode and the $\mathrm{TiO}_{2} / \mathrm{Ti}$ anode was $7.5 \mathrm{~mm}$. $\mathrm{TiO}_{2}$ was deposited onto $\mathrm{Ti}$ substrate by the dip-coating method. A certain amount of $\mathrm{Ti}\left(\mathrm{OC}_{4} \mathrm{H}_{9}\right)_{4}$ was dropwise added into $160 \mathrm{~mL}$ ethanol, then a small amount of $\mathrm{NH}\left(\mathrm{OC}_{2} \mathrm{H}_{5}\right)_{2}$ was added to this mixed solution. A light-yellow transparent solution was formed after being stirred with an ultrasonic horn for $15 \mathrm{~min}$. The ethanol solution ( $160 \mathrm{~mL}$ ) was mixed with the precursor solution with $48 \mathrm{~h}$ gelatinized [22]. A viscosity solution was obtained after $72 \mathrm{~h}$ sealed and gelatinized, which was coated onto titanium mesh by dip-coating method followed by calcination at $500{ }^{\circ} \mathrm{C}$ for $2 \mathrm{~h}$ [23].

The UV lamp (wavelength $254 \mathrm{~nm}$; $9 \mathrm{~W}$ ) was purchased from Nanjing Ziguang Company, China. In the experiment, the UV lamp was protected by a quartz tube. The UV lamp and quartz tube were fixed in the groove of the reactor. Meanwhile, the UV lamp was in concentric with the tubular $\mathrm{TiO}_{2} / \mathrm{Ti}$ mesh electrode. The motor supplies various steady state speeds (OS20-Pro, Dragon Laboratory

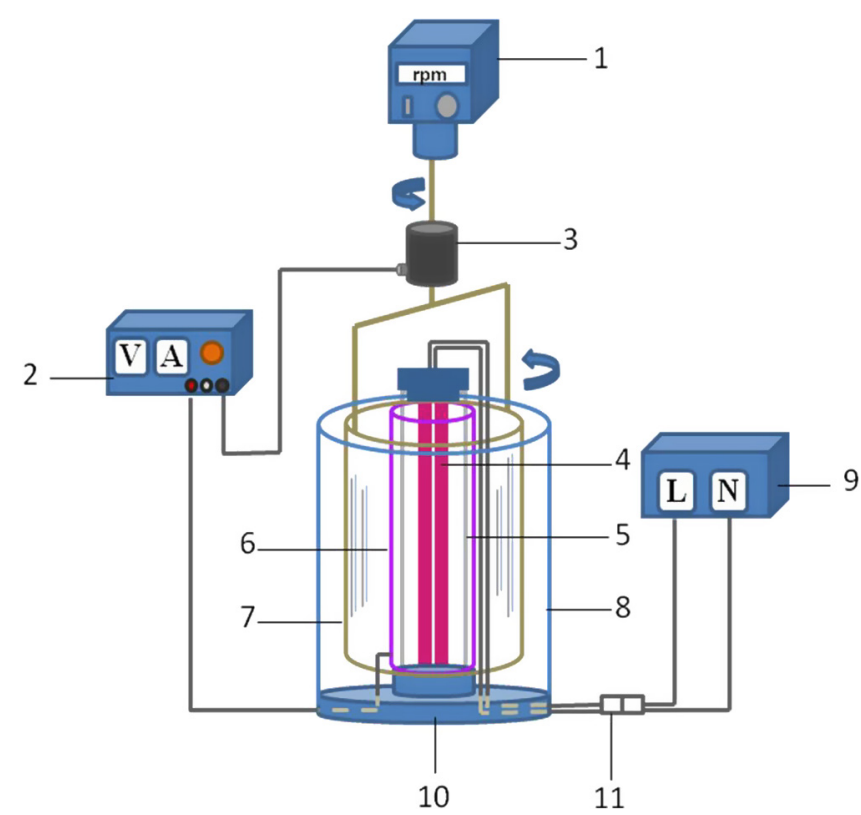

Fig. 1. The schematic view of the PEC system (1-Motor; 2-DC power; 3-Carbon body; 4-UV lamp; 5-Quartz tube; 6-Anode; 7-Cathode; 8-Reactor cell; 9-AC power; 10-Base; 11-Switch). 
Instruments Limited, Beijing, China). There was a carbon body as a link medium, which can connected the direct-current (DC) power and the rotating electrode of cathode. The power used in this study was provided by the DC power supply (DH1718E-6, Dahua Electronic, Co., Ltd., Beijing, China). To adjust the dissolved oxygen content in the solution, purging $\mathrm{N}_{2}(\geq 99.5 \%)$ and $\mathrm{O}_{2}(\geq 99.999 \%)$ into the system were performed before the experiment. The aeration duration was $30 \mathrm{~min}$ and the gas flow rate was $100 \mathrm{~mL} / \mathrm{min}$.

\subsection{Analytic procedures}

The concentration of $\mathrm{Cu}$ complexes was tested using a high performance liquid chromatograph (HPLC, 1260, Agilent Technology) with the Hypersil Gold (Thermo Scientific) analytical column, the elution comprised of $8 \%$ acetonitrile $(\mathrm{v} / \mathrm{v}) / 92 \%$ oxalic acid $(15 \mathrm{mM})$ (at pH 3.0, flow rate: $1 \mathrm{~mL} / \mathrm{min}, 25^{\circ} \mathrm{C}, 254 \mathrm{~nm}$ ) [24]. The total metal ions concentrations in the solution were measured by ICP-OES (700 series Agilent Technology, U.S.A). Total organic carbon (TOC) was tested by a Shimadzu TOC analyzer (TOC-VCPH, Shimadzu, Japan). The recovery ratio of metal ions $\left(\mathrm{R}_{\text {metal }}, \%\right)$ and TOC removal ratio ( $\left.\mathrm{R}_{\mathrm{TOC}}, \%\right)$ were defined by Eqs. (1) and (2):

$R_{\text {metal }}=\frac{\left(C_{\text {metal }, 0}-C_{\text {metal }, t}\right)}{C_{\text {metal }, 0}} \times 100 \%$

$R_{\mathrm{TOC}}=\frac{\left(C_{\mathrm{TOC}, 0}-C_{\mathrm{TOC}, t}\right)}{C_{\mathrm{TOC}, 0}} \times 100 \%$

The $C_{\text {metal }}\left(\mathrm{mg} \cdot \mathrm{L}^{-1}\right)$ is the metal ions concentration in the solution; $C_{T O C}\left(\mathrm{mg} \cdot \mathrm{L}^{-1}\right)$ is the TOC concentration of the simulated wastewater. The subscript 0 and $t$ respectively represent the initial and the sampling time.

Hydroxyl radicals were tested on a Bruker ESP-300E electron spin resonance (ESR) detector. The surface morphology of the recovered metal on the cathode was observed by the scanning electron microscope (SEM, model 6700F, Tokyo, Japan); the components of the cathode were analyzed by energy dispersive X-ray (EDX, JEOL, Japan). The pH value was tested by the Orion-828 (Beverly, MA) pH analyzer connected with a 9165 BN pH electrode.

\section{Results and discussion}

\subsection{Performance comparison of photodegradation, photocatalysis, electrolysis and PEC process}

Firstly, the recovery of $\mathrm{Cu}^{2+}$ ions and destruction of $\mathrm{Cu}$ complexes by different processes including photodegradation (UV), photocatalysis (PC), electrolysis (EC) and PEC process under the same $\mathrm{Cu}-\mathrm{EDTA}$ concentration, cathode rotation speed, initial $\mathrm{pH}$ and current density were estimated in the reactor. According to Fig. 2(a), it can be seen that $74.18 \% \mathrm{Cu}$ complexes was degraded and $75.54 \% \mathrm{Cu}^{2+}$ ions was recovered in the PEC process at $120 \mathrm{~min}$. By contrast, the recovery percentages of $\mathrm{Cu}^{2+}$ ions in individual EC and PC processes are $39.45 \%$ and $0.8 \%$, respectively. There was almost no degradation of $\mathrm{Cu}$ complexes and no recovery of $\mathrm{Cu}$ in the UV process. The kinetics constants of the recovery rate of $\mathrm{Cu}^{2+}$ ions were calculated by first-order reaction equation, which were $0.004\left(R^{2}=0.967\right), \quad 0.191 \quad\left(R^{2}=0.997\right)$ and $0.380 \mathrm{~h}^{-1}$ $\left(\mathrm{R}^{2}=0.995\right)$, in PC, EC and PEC process. For the removal of Cu complexes, the kinetics constants were $0.029\left(R^{2}=0.946\right), 0.188$ $\left(R^{2}=0.999\right)$ and $0.369 h^{-1}\left(R^{2}=0.996\right)$ respectively in PC, EC and PEC process. Evidently, the PEC process could achieve a much higher copper recovery compared to the individual PC and EC process.

As shown in Fig. 2(b), the variation of TOC was furthermore compared under the same experiment conditions. It can be seen
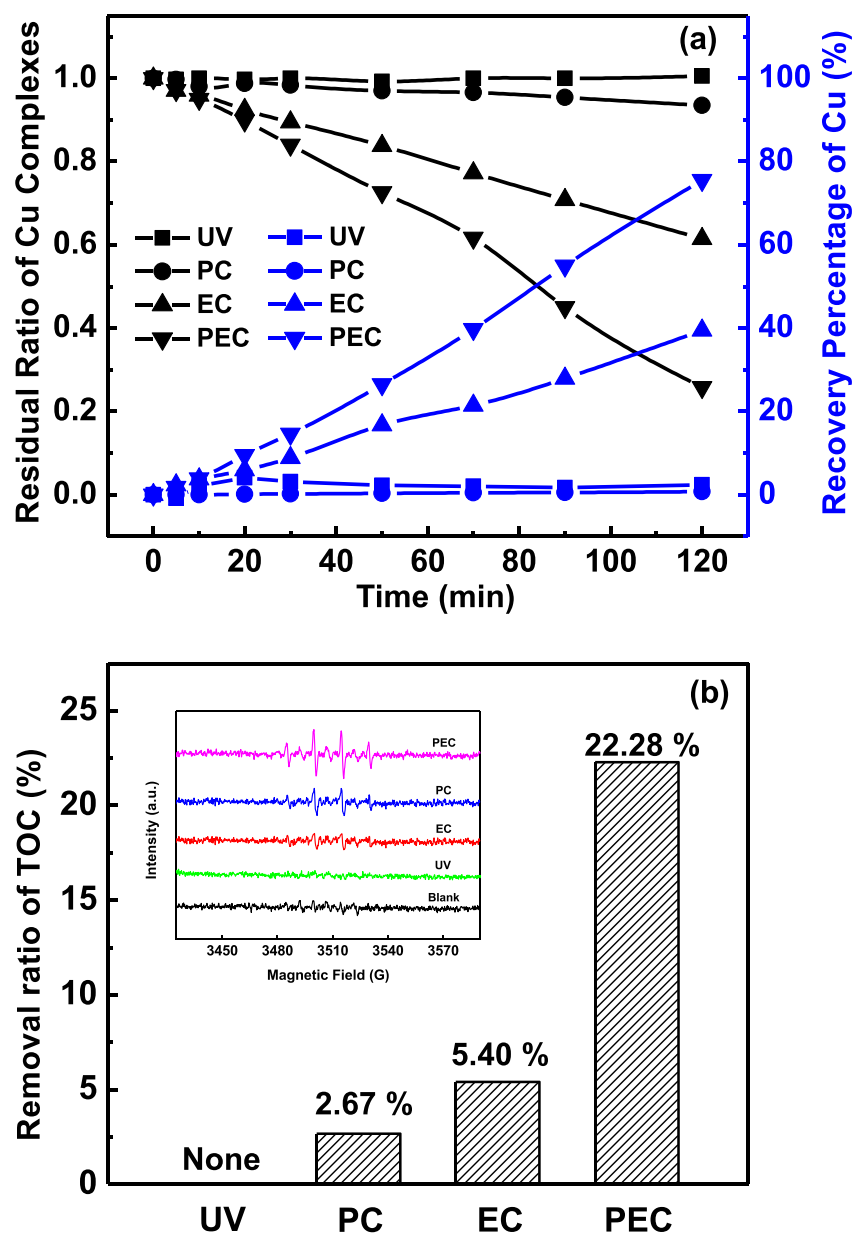

Fig. 2. (a) Recovery of $\mathrm{Cu}^{2+}$ ions and removal of $\mathrm{Cu}$ complexes via UV, PC, EC and PEC processes; (b) The removal efficiency of total organic carbon (inset DMPO spintrapping ESR spectra at ambient temperature) (initial concentration of Cu-EDTA $0.5 \mathrm{mM}$, rotating speed $=100 \mathrm{rpm}$, initial $\mathrm{pH}=3.18$, current density $=0.5 \mathrm{~mA} / \mathrm{cm}^{2}$ ).

that after $120 \mathrm{~min}$, TOC removal efficiencies are $2.67 \%, 5.40 \%$ and $22.28 \%$ for PC, EC and PEC process, respectively. And the results show that there is no TOC removal by individual photodegradation process. In addition, the peak intensity of DMPO-OH in these processes were given in the inset of Fig. 2 (b). The results indicate that the characteristic peak of DMPO- $\mathrm{OH}$ is the largest in the PEC process, which can effectively destroy the Cu-EDTA complexes [25]. So it can be proved that the TOC removal efficiency is significantly higher than that of PC and EC in the PEC process.

\subsection{Effect of rotating speed}

Generally, stir is one of the important methods to boost the relative concentration and mass transfer. The rotating speeds of the cathode were controlled at 0,50, 100, 150 and $200 \mathrm{rpm}$ to examine its effect on the recovery of $\mathrm{Cu}^{2+}$ ions and the degradation of $\mathrm{Cu}$ complexes. The rates of $\mathrm{Cu}^{2+}$ ions recovery and destruction of $\mathrm{Cu}$ complexes were strongly influenced by the rotating speed, as shown in Fig. 3. At $100 \mathrm{rpm}$ cathode rotation speed, initial $\mathrm{pH}$ of 3.18 and current density of $0.5 \mathrm{~mA} / \mathrm{cm}^{2}$, the recovery percentage of $\mathrm{Cu}$ and destruction of the $\mathrm{Cu}$ complexes were respectively $75.54 \%$ and $74.18 \%$ within 120 min (Fig. 3(a)). The recovery effect was obviously improved compared with the cathode with $0 \mathrm{rpm}$. Moreover, the degradation of $\mathrm{Cu}$ complexes in this rotation speed range was also enhanced. However, when the rotating speed of 

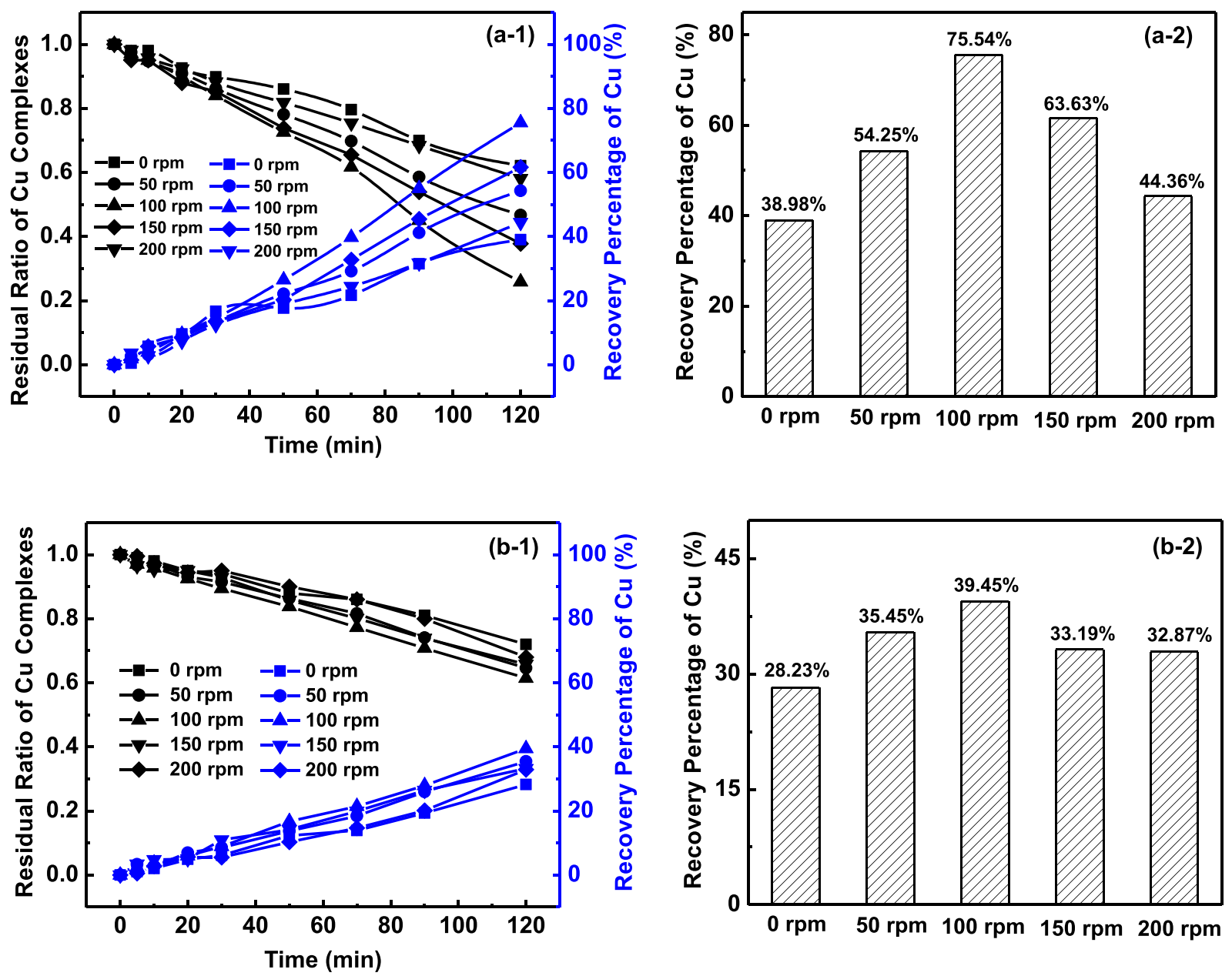

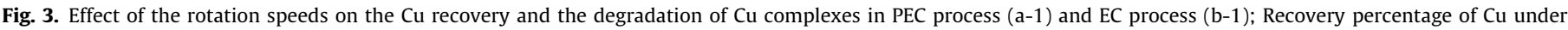
various rotating rate in PEC process (a-2) and EC process (b-2). (initial $\mathrm{Cu}$-EDTA concentration $0.5 \mathrm{mM}$, current density $=0.5 \mathrm{~mA} / \mathrm{cm}^{2}$, initial $\mathrm{pH}=3.18$ ).

cathode reached $200 \mathrm{rpm}$, the $\mathrm{Cu}^{2+}$ ions recovery rate and $\mathrm{Cu}$ complexes destruction rate was decreased.

At the relatively low rotating speed operation, the mass transfer of the solution was enhanced by the rotation of the cathode. The contact probability was greatly increased between metal ions and cathode surface. Therefore, the amount of metal ions on the cathode surface was increased. When the rotating speed of the cathode was too high, the contact area decreased between the inner surface of the cathode plate and the solution in the reactor under the action of centrifugal force. At the same time, it also hindered the stable reduction process of metal ions on the cathode surface with the high stirring speed [26]. Similar results were also observed in the EC process, as shown in Fig. 3(b). Taking into account the above results, the optimal stirring speed was selected as $100 \mathrm{rpm}$ in this system.

\subsection{Effect of the current density}

The effect of current density on the $\mathrm{Cu}^{2+}$ recovery and destruction of $\mathrm{Cu}$ complexes was investigated with $0.5 \mathrm{mM} \mathrm{Cu}$-EDTA under initial pH 3.18 and the rotation speed of $100 \mathrm{rpm}$ in PEC process. As shown in Fig. 4(a) and (b), when the current density was $0.25 \mathrm{~mA} / \mathrm{cm}^{2}$, the recovery percentage of $\mathrm{Cu}^{2+}$ ions and destruction of $\mathrm{Cu}$ complexes were $24 \%$ and $22 \%$, respectively. Nevertheless, recovery percentage of $\mathrm{Cu}^{2+}$ ions was nearly $100 \%$ and the destruc- tion rate of $\mathrm{Cu}$ complexes can be as high as $98 \%$ when the current density was $1.0 \mathrm{~mA} / \mathrm{cm}^{2}$. The recovery ratios of $\mathrm{Cu}^{2+}$ ions and removal rates of $\mathrm{Cu}$ complexes were increased with the current density evidently. With the increase of current density, the separation efficiency of photo-generated electrons and holes was increased. And the cathodic reduction efficiency of liberated copper ions was enhanced at the same time. A similar trend was reported in our previous work [27].

In the actual wastewater treatment, both of the efficient recovery of metals and low energy consumption were needed to be taken into account. In this PEC process, the energy consumption mainly derived from the electricity consumption of electrochemical reaction and UV lamp. The electricity consumption was evaluated with a standard of $1 \mathrm{~g} \mathrm{Cu}$ recovery under different current densities, and according to the equation as follows (3):

$W\left(\mathrm{kwh} \cdot \mathrm{g}^{-1}\right)=\frac{(U \times I+P) \times t}{\Delta x \times 1000}$

The $W\left(\mathrm{kwh} \cdot \mathrm{g}^{-1}\right)$ is the electricity consumption of the reaction process. $U$ and $I$ respectively indicate the actual voltage and the actual current during operation, and the corresponding units are volt $(\mathrm{V})$ and ampere $(\mathrm{A})$. The $P$ stands for ultraviolet lamp power, and the unit is watt $(\mathrm{W})$. The $t$ represents the reaction time, and the unit is hour (h). The $\Delta x$ indicate the recovery quality of copper ion, and the unit is milligramma ( $\mathrm{mg}$ ). 

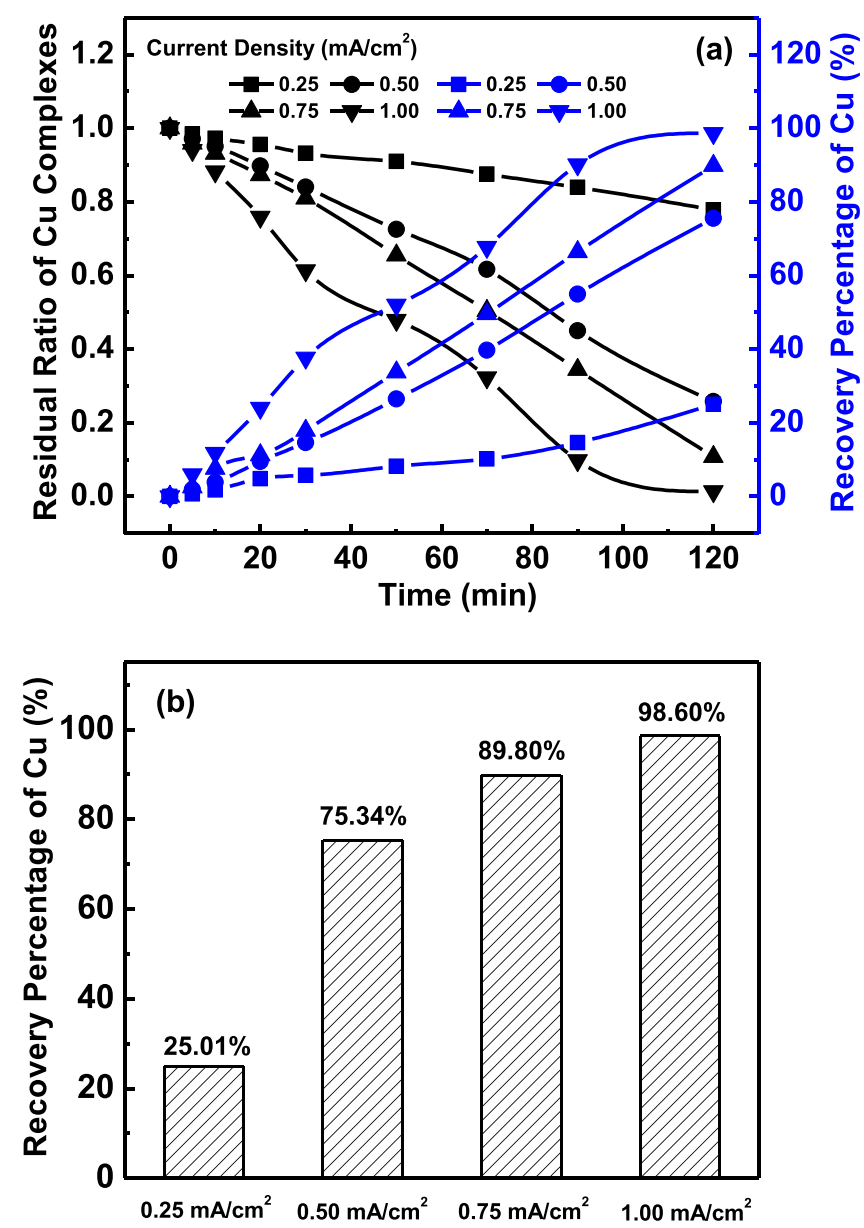

Fig. 4. Effect of current density on the $\mathrm{Cu}$ recovery and the degradation of $\mathrm{Cu}$ complexes in PEC process (a); Recovery percentage of $\mathrm{Cu}$ under various current density in PEC process (b) (initial Cu-EDTA concentration $0.5 \mathrm{mM}$, rotating speed $=100 \mathrm{rpm}$, initial $\mathrm{pH}=3.18$ ).

Table 1

The energy consumption for recovery of $1 \mathrm{~g}$ Cu under different current density.

\begin{tabular}{llll}
\hline Current Density $\left(\mathrm{mA} / \mathrm{cm}^{2}\right)$ & Current $(\mathrm{I})$ & Voltage $(\mathrm{V})$ & Energy $\left(\mathrm{Kwh} \cdot \mathrm{g}^{-1}\right)$ \\
\hline 0.25 & 0.034 & 4.55 & $3812 \times 10^{-3}$ \\
0.50 & 0.068 & 6.59 & $1303 \times 10^{-3}$ \\
0.75 & 0.102 & 8.32 & $1145 \times 10^{-3}$ \\
1.00 & 0.136 & 9.52 & $1087 \times 10^{-3}$ \\
\hline
\end{tabular}

Under the current density of $0.25,0.50,0.75$, and $1.00 \mathrm{~mA} / \mathrm{cm}^{2}$, the measured operating voltage was $6.59,8.32,4.55,9.52 \mathrm{~V}$, respectively. The UV lamp power kept at a constant value of $9 \mathrm{~W}$ for all the experiments. As shown in Table 1, the energy consumption was reduced with the increase of the current density. Considering the energy cost and the recovery efficiency, the current density was chosen as $5 \mathrm{~mA} / \mathrm{cm}^{2}$ in the present experiment.

\subsection{Effect of the initial $\mathrm{pH}$}

The effect of solution $\mathrm{pH}$ on the removal of $\mathrm{Cu}$ complexes and recovery of $\mathrm{Cu}^{2+}$ ions at the rotating speed of $100 \mathrm{rpm}$ in PEC process was investigated. The initial $\mathrm{pH}$ of the $\mathrm{Cu}-\mathrm{EDTA}$ solution without any adjustment is 3.18. As shown in Fig. 5, the recovery efficiency of $\mathrm{Cu}^{2+}$ ions at the initial $\mathrm{pH} 3.18,5.00,7.00$, and 9.00 were $75.54 \%, 13.31 \%, 13.68 \%$, and $16.89 \%$. And the kinetic constants of $\mathrm{Cu}^{2+}$ recovery in the PEC process were $0.0105,0.0009,0.0009$,
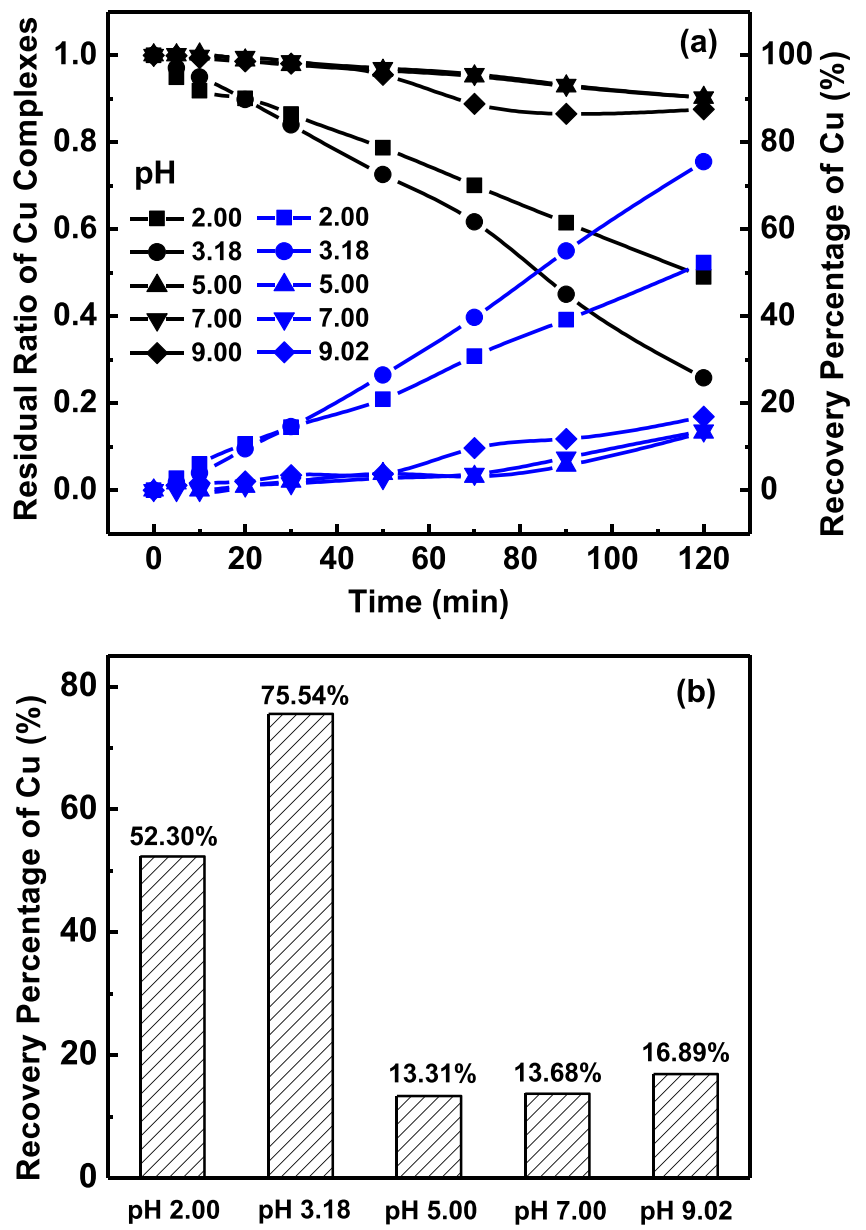

Fig. 5. Effect of initial $\mathrm{pH}$ on the $\mathrm{Cu}$ recovery and the degradation of $\mathrm{Cu}$ complexes in PEC process (a); Recovery percentage of $\mathrm{Cu}$ under various initial $\mathrm{pH}$ in PEC process (b) (initial concentration of $\mathrm{Cu}-\mathrm{EDTA}=0.5 \mathrm{mM}$, rotating speed $=100 \mathrm{rpm}$, current density $=0.5 \mathrm{~mA} / \mathrm{cm}^{2}$ ).

and $0.0012 \mathrm{~h}^{-1}$, respectively. The kinetic constants decreased with the $\mathrm{pH}$ increasing. Meantime, the removal of $\mathrm{Cu}$-EDTA decreased with the $\mathrm{pH}$ increasing. Moreover, the degradation of $\mathrm{Cu}$ complexes and the recovery efficiency of $\mathrm{Cu}$ were decreased when the $\mathrm{pH}$ value was 2.00 .

It was reported that in the case of photocatalysis of Cd-EDTA by $\mathrm{TiO}_{2}$, at low $\mathrm{pH}$ values, a large portion of the complex was adsorbed; under high $\mathrm{pH}$ conditions, the complex existed mostly in solution [28]. In our previous work, it was found that Cu-EDTA species depended upon the solution $\mathrm{pH}$ value, such as (CuEDTA) ${ }^{2-}$, $\mathrm{CuH}_{2}$ EDTA, (CuHEDTA) ${ }^{-}$, and CuOHEDTA ${ }_{3}^{-}$. At pH 5.0, 7.0, and 9.0, the major species of the $\mathrm{Cu}$-EDTA complexes in the solution were the fully deprotonated form of (CuEDTA $)^{2-}$. At $\mathrm{pH} 3.18$, the major species were (CuHEDTA) ${ }^{-}$and (CUEDTA) ${ }^{2-}$, as well as a small amount of possible existing $\mathrm{CuH}_{2}$ EDTA in the solution. It is possible that ${ }^{\circ} \mathrm{OH}$ radicals can react with (CUHEDTA) ${ }^{-}$better than with $(\text { CuEDTA })^{2-}[29]$. On the other hand, the liberated $\mathrm{Cu}^{2+}$ may precipitate as $\mathrm{CuO}$ or $\mathrm{Cu}_{2} \mathrm{O}$ when the $\mathrm{pH}$ was higher than 5.0, which were not available for the electrochemical reduction [9]. Herein, the reaction rate was higher at $\mathrm{pH} 3.18$ than $\mathrm{pH} 5.00,7.00$, and 9.00. In addition, at $\mathrm{pH} 2.00$, the major species were $\mathrm{Cu}^{2+}, \mathrm{CuH}_{2}$ EDTA and a small ratio of $\mathrm{H}_{4}$ EDTA, which was not beneficial for the degradation by $\mathrm{OH}$ oxidation, resulting in a low degradation efficiency of $\mathrm{Cu}$ complexes as well as low recovery efficiency of $\mathrm{Cu}$ at $\mathrm{pH} 2.00$ due to $\mathrm{H}_{2}$ evolution. 

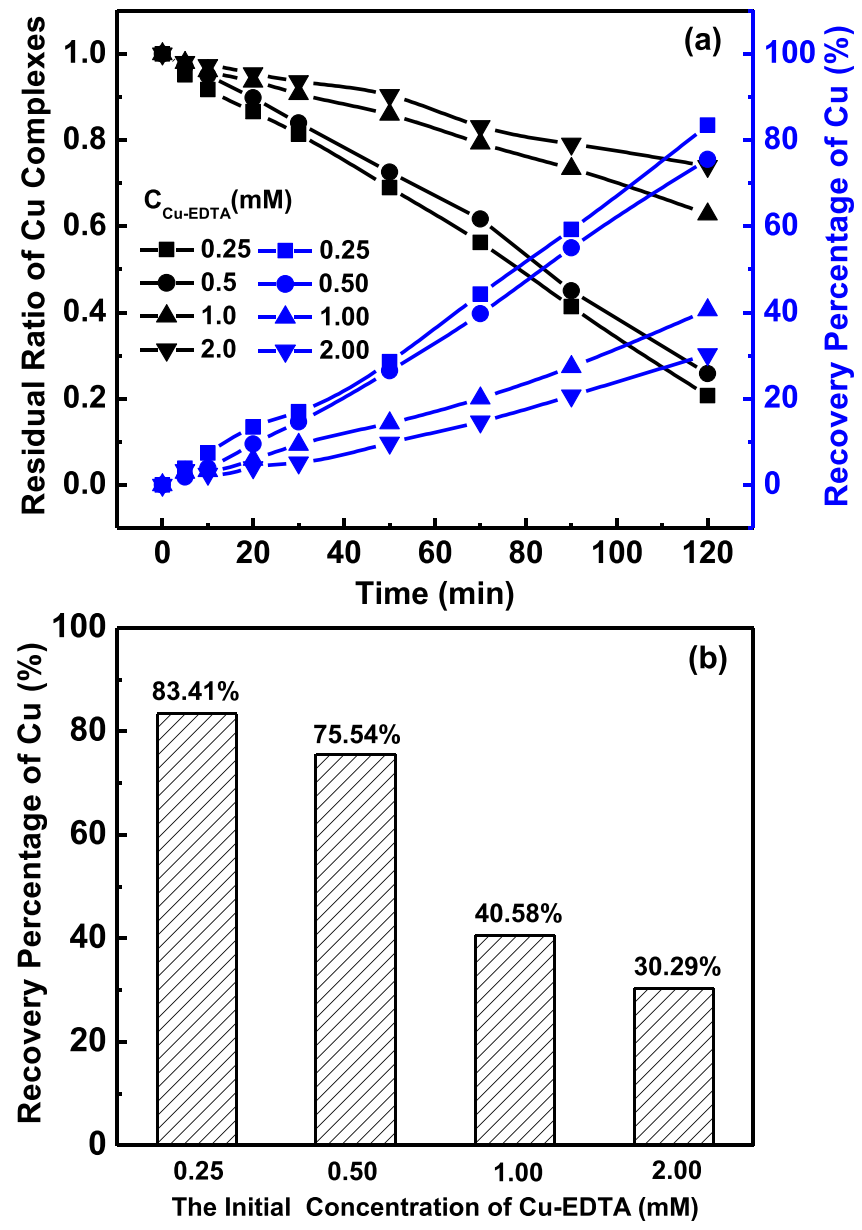

Fig. 6. Effect of initial concentrations on the Cu recovery and the degradation of $\mathrm{Cu}$ complexes in PEC process (a); Recovery percentage of $\mathrm{Cu}$ under various initial concentrations in PEC process (b) (rotating speed $=100 \mathrm{rpm}$, current density $=0.5 \mathrm{~mA} / \mathrm{cm}^{2}$, initial $\mathrm{pH}=3.18$ ).

\subsection{Effect of the initial concentration of Cu-EDTA}

The performance of $\mathrm{Cu}^{2+}$ ions recovery and $\mathrm{Cu}$ complexes destruction with various initial Cu-EDTA concentrations was evaluated. As shown in Fig. 6, the proportion of $\mathrm{Cu}^{2+}$ ions recovery and $\mathrm{Cu}$ complexes destruction increases with the decrease of initial $\mathrm{Cu}$ EDTA concentration. The recovery rate of $\mathrm{Cu}^{2+}$ ions reached $83 \%$ at initial $0.25 \mathrm{mM} \mathrm{Cu}$-EDTA. By contrast, when the initial concentration of $\mathrm{Cu}$-EDTA was $2.00 \mathrm{mM}$, the recovery rate of $\mathrm{Cu}^{2+}$ ions was only $30 \%$ at $120 \mathrm{~min}$. The destruction of $\mathrm{Cu}$ complexes was followed by the $\mathrm{Cu}^{2+}$ electrodeposition according to our previous results [8]. On one hand, the amount of the same electron transfer may electrodeposit equivalent quantity $\mathrm{Cu}^{2+}$ ions on the cathode under the same conditions of PEC process. On the other hand, the competitive adsorption onto the active site occurred between $\mathrm{Cu}$ EDTA and its intermediates at high initial concentration of $\mathrm{Cu}-$ EDTA [9].

\subsection{Aeration condition}

The effect of aeration on the PEC process in the reactor was also investigated. In order to avoid the influence of aeration on mass transfer efficiency, purging $\mathrm{N}_{2}(\geq 99.5 \%)$ and $\mathrm{O}_{2}(\geq 99.999 \%)$ into the system were performed before the experiment. The aeration duration was $30 \mathrm{~min}$ and the gas flow rate was $100 \mathrm{~mL} / \mathrm{min}$. The best performance in the $\mathrm{Cu}^{2+}$ ions recovery process was obtained
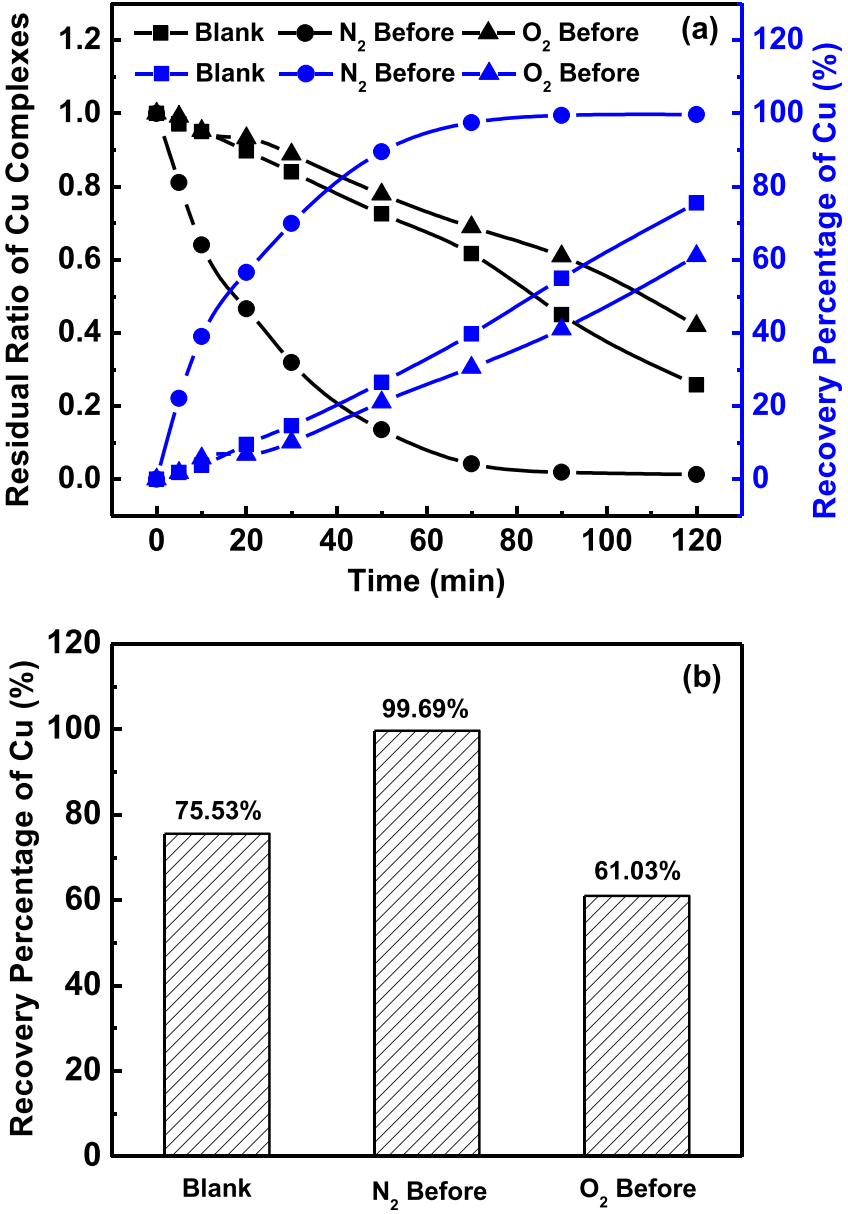

Fig. 7. Effect of aeration condition on the Cu recovery and the degradation of $\mathrm{Cu}$ complexes in PEC process (a); Recovery percentage of $\mathrm{Cu}$ under aeration condition in PEC process (b) (initial concentration of $\mathrm{Cu}-\mathrm{EDTA}=0.5 \mathrm{mM}$, rotating speed $=100 \mathrm{rpm}, \quad$ initial $\mathrm{pH}=3.18$, current density $=0.5 \mathrm{~mA} / \mathrm{cm}^{2}$, gas flow $=100 \mathrm{~mL} / \mathrm{min}$ )

when the solution was purged with $\mathrm{N}_{2}$ before. As shown in Fig. 7, the recovery percentage of $\mathrm{Cu}$ reaches $97.47 \%$ at $90 \mathrm{~min}$ by the aeration of $\mathrm{N}_{2}$. However, the recovery ratio of $\mathrm{Cu}^{2+}$ after $120 \mathrm{~min}$ is diminished by about $14.51 \%$ after purging with $\mathrm{O}_{2}$. The degradation trend of $\mathrm{Cu}$ complexes is almost the same with that of $\mathrm{Cu}^{2+}$ recovery.

There was a competitive relationship between the $\mathrm{Cu}^{2+}$ ions and $\mathrm{O}_{2}$. The dissolved oxygen in the solutions can occupy the active sites on the cathode and inhibit the cathodic reduction of the liberated $\mathrm{Cu}^{2+}$ ions. When $\mathrm{N}_{2}$ was pumped into the PEC reactor, and the dissolved oxygen was excluded, thereby improving the efficiency of $\mathrm{Cu}^{2+}$ ions recovery.

\subsection{Performance for various metal-EDTA complexes}

To gain an insight into the ability of the recovery of metal ions and removal of metal-EDTA within the reactor, several metal-EDTA complexes were tested including Co-EDTA, Ni-EDTA, and Zn-EDTA. The initial $\mathrm{pH}$ of these metal-EDTA solutions were $3.20,3.18$, and 3.22 , respectively. In the section, the initial concentrations of all the metal-EDTA were $0.5 \mathrm{mM}$. As seen in Fig. 8, it is obvious that the recovery efficiency of the various divalent metals increased significantly through the PEC reactor. The recovery of $\mathrm{Co}^{2+}$ ions was determined to be $14 \%$ and $60 \%$ at the rotation speed of $0 \mathrm{rpm}$ and $50 \mathrm{rpm}$; the recovery of $\mathrm{Ni}^{2+}$ ions was determined to be $10 \%$ 

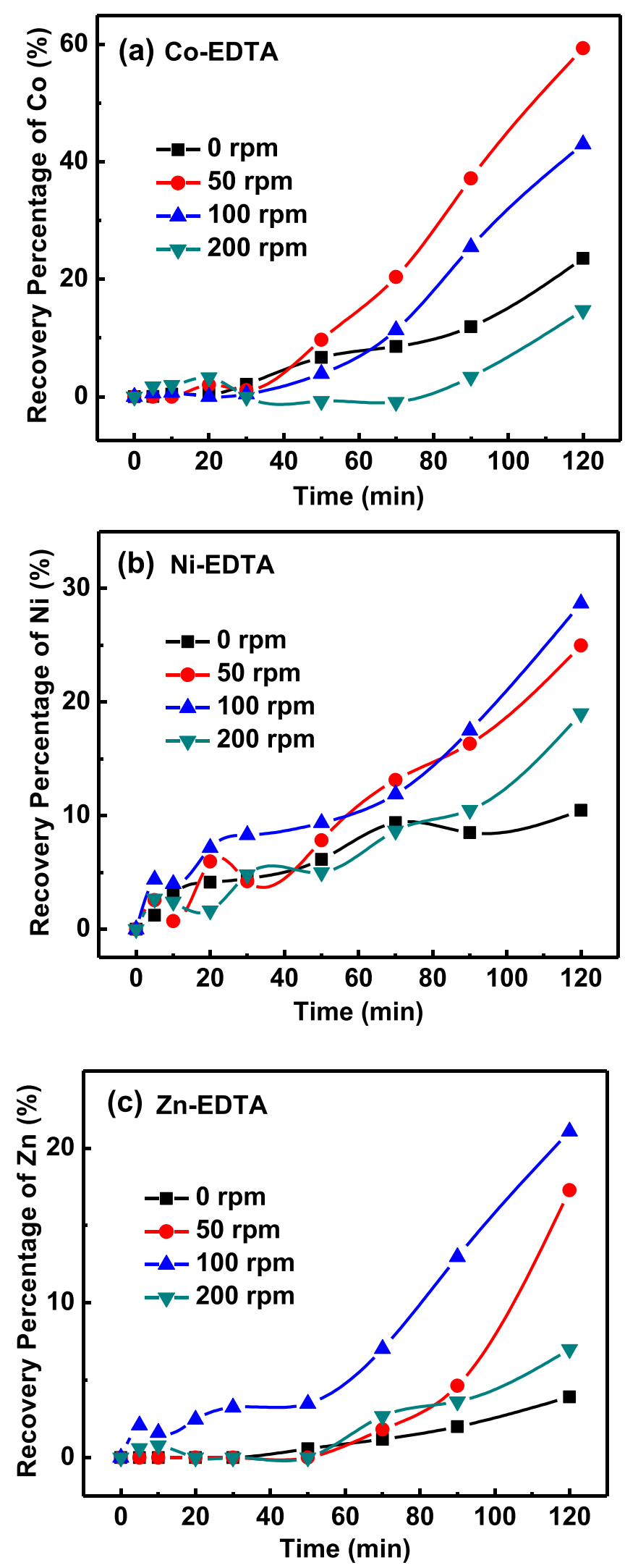

Fig. 8. Recovery of metal ions (a) Co-EDTA; (b) Ni-EDTA; (c) Zn-EDTA (initial metals-EDTA concentration $=0.5 \mathrm{mM}$, current density $=0.5 \mathrm{~mA} / \mathrm{cm}^{2}$ ). and $29 \%$ at the rotation speed of $0 \mathrm{rpm}$ and $100 \mathrm{rpm}$; and the recovery of $\mathrm{Zn}^{2+}$ ions was determined to be $3 \%$ and $21 \%$ at $0 \mathrm{rpm}$ and $100 \mathrm{rpm}$ under the same current density of $0.5 \mathrm{~mA} / \mathrm{cm}^{2}$, at the reaction time of $120 \mathrm{~min}$, respectively. The standard reduction potentials of these divalent metal cations were $-0.34 \mathrm{~V}(\mathrm{Cu})$, $-0.28 \mathrm{~V}(\mathrm{Co}),-0.23 \mathrm{~V}(\mathrm{Ni}),-0.763 \mathrm{~V}(\mathrm{Zn})$ at $298 \mathrm{~K}$. It was proposed that the reduction potentials influenced the recovery capacity of liberated metal ions in the cathodic reduction.

\subsection{Surface morphology analyses of the rotating cathode}

Furthermore, the surface morphology of the rotating cathode in treating various metal-EDTA complexes in the PEC process was characterized by SEM and EDX analyses. It can be seen from Fig. 9 that a large amount of metal of a single element was electrodeposited onto the cathode of $\mathrm{Ti}$ and the rotating cathode was nearly covered completely. It can also be seen from the EDX analysis in Fig. 9 that the material composition of the rotating cathode after reaction was consisted of Ti and metal elements. The atomic percentage of metals with Ti on the cathode followed the order of $\mathrm{Cu}>\mathrm{Co}>\mathrm{Ni}>\mathrm{Zn}$. This result was consistent with the recovery ratio of metals ions as shown in Fig. 8.

\subsection{Stability of the PEC system}

The stability of the PEC reactor for the recovery ratio of metal ions and the removal percentage of metal-EDTA was studied by the duplicate use of the same $\mathrm{TiO}_{2} / \mathrm{Ti}$ anode and the same rotating cathode for ten successive cycles. In this part, $0.5 \mathrm{mM} \mathrm{Cu-EDTA}$ and the rotating speed of $100 \mathrm{rpm}$ was selected. As shown in Fig. 10, in the first cycle, the recovery of $\mathrm{Cu}^{2+}$ ions and destruction of $\mathrm{Cu}$ complexes were close to $100 \%$. And there was a certain downward trend along with the increase of the reaction cycle in the first five cycles. It remains nearly constant, in which the recovery percentages of $\mathrm{Cu}^{2+}$ ions are determined to be $76 \%, 80 \%, 77 \%, 75 \%, 76 \%$ and $78 \%$, respectively. In the meantime, the same change trend was also observed for $\mathrm{Cu}$ complexes degradation. The experimental results show that the reactor had better treatment performance in the earlier period. Finally, it tended to be a relatively favorable and stable state after a downward trend in several cycles.

\section{Conclusions}

The PEC reactor with the rotating cathode can achieve an efficient recovery of liberated metal ions onto the rotating cathode surface and destruction of metal complexes. The UV photodegradation, PC, EC, and PEC processes were used to compare the degradation of $\mathrm{Cu}$ complexes. Results showed that the PEC process exhibited a synergistic effect on the $\mathrm{Cu}$ recovery and $\mathrm{Cu}$ complexes destruction. The recovery percentage of $\mathrm{Cu}$ and destruction of the $\mathrm{Cu}$ complexes were increased to $75.54 \%$ and $74.18 \%$ when the cathode rotation speed was $100 \mathrm{rpm}$ at initial $\mathrm{pH}$ of 3.18 and current density of $0.5 \mathrm{~mA} / \mathrm{cm}^{2}$ within $120 \mathrm{~min}$. Before the start of the reaction, purging $\mathrm{N}_{2}$ into the system can obviously promote the recovery of $\mathrm{Cu}$ on the cathode, and thus improved the degradation of $\mathrm{Cu}$ complexes. Meanwhile, the capacity of the reactor was investigated by the recovery of different metals. Such as Co-EDTA, NiEDTA and $\mathrm{Zn}$-EDTA complexes, the $\mathrm{Co}^{2+}, \mathrm{Ni}^{2+}$ and $\mathrm{Zn}^{2+}$ recovery rate increased by $29 \%, 19 \%$ and $18 \%$ in the adjustment speed for the optimal parameters of cathode. And the recovery product from the cathodic electroreduction was all elemental crystal. Thus, it can 


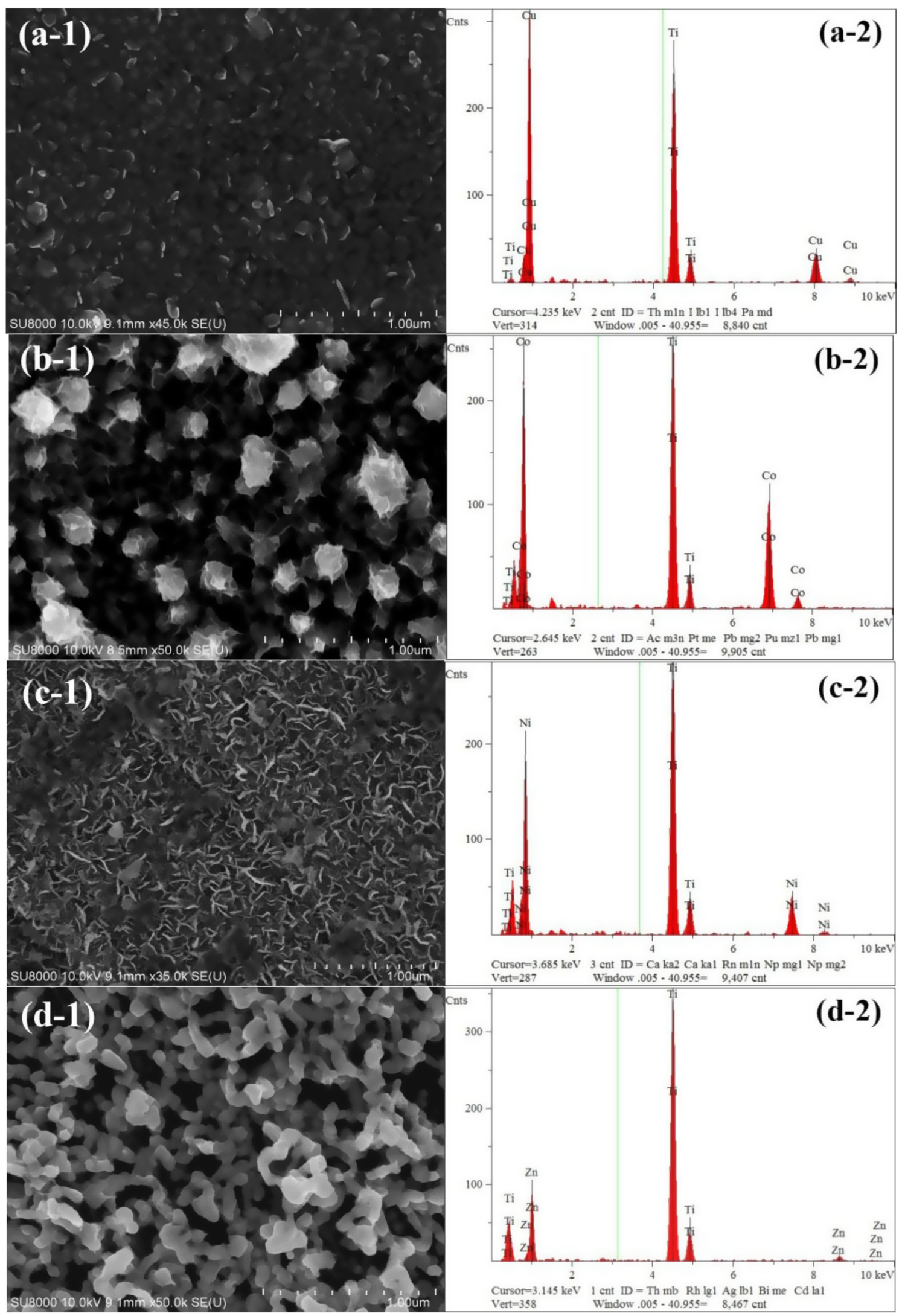

Fig. 9. SEM analysis of the cathode electrodeposition with the (a-1) Cu-EDTA, (b-1) Co-EDTA, (c-1) Ni-EDTA and (d-1) Zn-EDTA solutions in the PEC process; EDX analysis of the cathode electrodeposition with the (a-2) Cu-EDTA, (b-2) Co-EDTA, (c-2) Ni-EDTA and (d-2) Zn-EDTA solutions in the PEC process. 


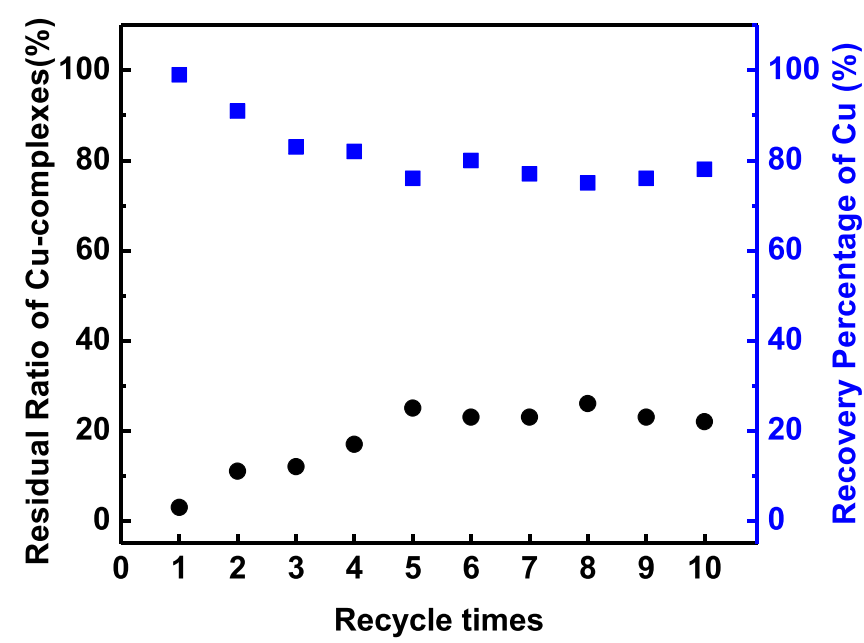

Fig. 10. The stability analysis of the PEC system reactor. (initial concentration of $\mathrm{Cu}-\mathrm{EDTA}=0.5 \mathrm{mM}$, rotating speed $=100 \mathrm{rpm}$, initial $\mathrm{pH}=3.18$, current density $=0.5 \mathrm{~mA} / \mathrm{cm}^{2}$ ).

be concluded that the electrodeposition of metal ions could be significantly enhanced by the rotation of the cathode in the PEC reactor.

\section{Acknowledgements}

This work was financially supported by projects of the National Key Research and Development Program of China (No. 2016YFA0203101) and National Natural Science Foundation of P.R. China (No. 21377148, 51578532).

\section{References}

[1] O. Tunay, I. Kabdasli, R. Tasli, Pretreatment of complexed metal wastewater, Iwa Publishing 29 (1994) 265-274.

[2] M.E.T. Sillanpää, T.A. Kurniawan, W.H. Lo, Degradation of chelating agents in aqueous solution using advanced oxidation process (AOP), Chemosphere 83 (2011) 1443.

[3] J.K. Yang, A.P. Davis, Photocatalytic Oxidation of Cu(II)-EDTA with Illuminated TiO2: Kinetics, J. Card. Fail. 10 (2000) S124.

[4] R.S. Juang, L.C. Lin, Treatment of complexed Copper(II) solutions with electrochemical membrane processes, Water Res. 34 (2000) 43-50.

[5] D. Jiraroj, F. Unob, A. Hagège, Degradation of Pb-EDTA complex by a $\mathrm{H}_{2} \mathrm{O}_{2} / \mathrm{UV}$ process, Water Res. 40 (2006) 107.

[6] X. Zhao, L.B. Guo, C.Z. Hu, H.J. Liu, J.H. Qu, Simultaneous destruction of Nickel (II)-EDTA with $\mathrm{TiO}_{2} / \mathrm{Ti}$ film anode and electrodeposition of nickel ions on the cathode, Appl. Catal. B-Environ. 144 (2014) 478-485.

[7] G.G. Bessegato, T.T. Guaraldo, J.F. de Brito, M.F. Brugnera, M.V.B. Zanoni, Achievements and trends in photoelectrocatalysis: from environmental to energy applications, Electrocatalysis 6 (2015) 415-441.

[8] H.B. Zeng, S.S. Liu, B.Y. Chai, D. Cao, Y. Wang, X. Zhao, Enhanced photoelectrocatalytic decomplexation of Cu-EDTA and $\mathrm{Cu}$ recovery by persulfate activated by UV and cathodic reduction, Environ. Sci. Technol. 50 (2016) 6459-6466.

[9] X. Zhao, L.B. Guo, J.H. Qu, Photoelectrocatalytic oxidation of Cu-EDTA complex and electrodeposition recovery of $\mathrm{Cu}$ in a continuous tubular photoelectrochemical reactor, Chem. Eng. J. 239 (2014) 53-59.

[10] K. Juttner, U. Galla, H. Schmieder, Electrochemical approaches to environmental problems in the process industry, Electrochim. Acta 45 (2000) 2575-2594.

[11] T.C. An, G.Y. Li, X.H. Zhu, J.M. Fu, G.Y. Sheng, Z. Zhu, Photoelectrocatalytic degradation of oxalic acid in aqueous phase with a novel three-dimensional electrode-hollow quartz tube photoelectrocatalytic reactor, Appl. Catal. A-Gen. 279 (2005) 247-256.

[12] G. Palmisano, V. Loddo, H.H. El Nazer, S. Yurdakal, V. Augugliaro, R. Ciriminna, M. Pagliaro, Graphite-supported $\mathrm{TiO}_{2}$ for 4-nitrophenol degradation in a photoelectrocatalytic reactor, Chem. Eng. J. 155 (2009) 339-346.

[13] Y.L. Xu, Y. He, X.D. Cao, D.J. Zhong, J.P. Jia, $\mathrm{TiO}_{2} / \mathrm{Ti}$ rotating disk photoelectrocatalytic (PEC) reactor: A combination of highly effective thinfilm PEC and conventional PEC processes on a single electrode, Environ. Sci. Technol. 42 (2008) 2612-2617.

[14] Y. Zhang, M.M. Gao, X.H. Wang, S.G. Wang, R.T. Liu, Enhancement of oxygen diffusion process on a rotating disk electrode for the electro-Fenton degradation of tetracycline, Electrochim. Acta 182 (2015) 73-80.

[15] I.M. Butterfield, P.A. Christensen, A. Hamnett, K.E. Shaw, G.M. Walker, S.A Walker, C.R. Howarth, Applied studies on immobilized titanium dioxide films as catalysts for the photoelectrochemical detoxification of water, J. Appl. Electrochem. 27 (1997) 385-395.

[16] D.D. Dionysiou, G. Balasubramanian, M.T. Suidan, A.P. Khodadoust, I. Baudin, M. Laine, Rotating disk photocatalytic reactor: Development, characterization, and evaluation for the destruction of organic pollutants in water, Water Res. 34 (2000) 2927-2940.

[17] Y.L. Xu, Y. He, J.P. Jia, D.J. Zhong, Y.L. Wang, Cu-TiO $/ 2 /$ i Dual Rotating Disk Photocatalytic (PC) Reactor: dual electrode degradation facilitated by spontaneous electron transfer, Environ. Sci. Technol. 43 (2009) 6289-6294.

[18] A.R. Alonso, G.T. Lapidus, I. Gonzalez, Selective silver electroseparation from ammoniacal thiosulfate leaching solutions using a rotating cylinder electrode reactor (RCE), Hydrometallurgy 92 (2008) 115-123.

[19] A. Recendiz, S. Leon, J.L. Nava, F.F. Rivera, Mass transport studies at rotating cylinder electrode during zinc removal from dilute solutions, Electrochim. Acta 56 (2011) 1455-1459.

[20] J.R. Hernandez-Tapia, J. Vazquez-Arenas, I. Gonzalez, Electrochemical reactor with rotating cylinder electrode for optimum electrochemical recovery of nickel from plating rinsing effluents, J. Hazard. Mater. 262 (2013) 709-716.

[21] Y. Lei, C.S. Chen, Y.J. Tu, Y.H. Huang, H. Zhang, Heterogeneous degradation of organic pollutants by persulfate activated by $\mathrm{CuO}-\mathrm{Fe}_{3} \mathrm{O}_{4}$ : mechanism, stability, and effects of pH and bicarbonate ions, Environ. Sci. Technol. 49 (2015) 6838.

[22] J. Shang, W. Li, Y.F. Zhu, Structure and photocatalytic characteristics of $\mathrm{TiO}_{2}$ film photocatalyst coated on stainless steel webnet, J. Mol. Catal. A-Chem. 202 (2003) 187-195.

[23] Y. Cong, Z. Li, Y. Zhang, Q. Wang, Q. Xu, Synthesis of $\alpha-\mathrm{Fe}_{2} \mathrm{O}_{3} / \mathrm{TiO}_{2}$ nanotube arrays for photoelectro-Fenton degradation of phenol, Chem. Eng. J. 191 (2012) 356-363.

[24] X. Zhao, J.J. Zhang, J.H. Qu, Photoelectrocatalytic Oxidation of Cu-cyanides and $\mathrm{Cu}-\mathrm{EDTA}$ at $\mathrm{TiO}_{2}$ nanotube electrode, Electrochim. Acta 180 (2015) 129-137.

[25] A. Vogelpohl, S.M. Kim, Advanced oxidation processes (AOPs) in wastewater treatment, J. Ind. Eng. Chem. 10 (2004) 33-40.

[26] A. Recéndiz, S. León, J.L. Nava, F.F. Rivera, Mass transport studies at rotating cylinder electrode during zinc removal from dilute solutions, Electrochim. Acta 56 (2011) 1455-1459.

[27] X. Zhao, J.H. Qu, H.J. Liu, C.X. Wang, S.H. Xiao, R.P. Liu, P.J. Liu, H.C. Lan, C.Z. Hu, Photoelectrochemical treatment of landfill leachate in a continuous flow reactor, Bioresour. Technol. 101 (2010) 865-869.

[28] J.K. Yang, A.P. Davis, Competitive Adsorption of Cu(II)-EDTA and Cd(II)-EDTA onto $\mathrm{TiO}_{2}$, J. Colloid Interface Sci. 216 (1999) 77-85.

[29] X. Zhao, L.B. Guo, B.F. Zhang, H.J. Liu, J.H. Qu, Photoelectrocatalytic oxidation of $\mathrm{Cu}^{\mathrm{II}}$-EDTA at the $\mathrm{TiO}_{2}$ electrode and simultaneous recovery of $\mathrm{Cu}^{\mathrm{II}}$ by electrodeposition, Environ. Sci. Technol. 47 (2013) 4480-4488. 